\title{
Reflections on Digestions and Other Corporealities in Artists' Books
}

\author{
Amanda Couch, \\ Email amandajcouch@gmail.com \\ University for the Creative Arts, Farnham, UK
}

\section{Abstract}

With an avid attention to the valuing of embodiment and a championing of the re-emergence of the body as site for discussions of knowledge and knowing, this essay shares aspects of my practice that engage a performative, haptic, situated engagement with the body through the artist's book. The motivation for the creation of my bookworks was an interest in manifesting situated knowing and embodied ways of becoming. Engaging form, materiality, and bodily history, my artists' books explore the processes and metaphors of digestion and in one example, mindfulness practice. In libraries and collections with links to health, my artists' books can be experienced in teaching and research contexts to examine the body, health, illness and wellbeing. This essay focuses on my books which communicate embodied knowledge in several ways: through phenomenological writing to give expression to my irritable bowel syndrome (IBS) and how it impacts on my teaching practice in Reflection on Digestion; through bodily material of Entrail Troyen; through the image of the digestive system in On Innards, Reflection on Digestion, and Entrail Troyen, particularly the concertina form emulating the undulations of the intestines; and through images of found objects that resemble the bowels in Huwawa in the Everyday.

\section{Keywords}

Embodiment

Artists' books

Materiality

Digestion

Intestines 


\section{Introduction}

Cutting across media, my art practice researches and reimagines histories of the body, particularly the digestive system, often triggered by the processes and lived experiences of my own body which are employed as material as well as metaphor. With an avid attention to the valuing of embodiment and a championing of the re-emergence of the body as site for discussions of knowledge and knowing, this essay shares aspects of my practice that engage a performative, haptic, situated engagement with the body through the artist's book.

When books were made of hide, it was not just the metaphorical anatomy of the book, evident in the terms 'spine,' 'footnotes,' 'appendix,' and in 'manuscript' (from the Latin manu, meaning hand) but the materiality of bodies through the "boundary-object" of skin (Ahmed and Stacey 2001, 2) which was the site of a performance between book and beholder. Fingers, palms, arms, breasts, legs, wherever a tome was placed, and the leather and parchment of books, enacted a corporeal connectivity through the haptic. Artists' books today often demand an intimate relationship with the beholder. They are democratic artworks that can be handled and brought into the realm of the body. 
The motivation for the creation of my bookworks was an interest in manifesting and enacting embodied ways of knowing and becoming. Engaging the form, materiality, bodily history, and idea of the book as a vessel that contains knowledge, my artists' books explore the processes and metaphors of digestion and reflexivity and in one example, mindfulness practice. Martha Hall considered her artists' books as "a means to effect change" $(2003,15)$, "to build better relationships" with her doctors (13). ${ }^{1}$ Now in libraries and collections with links to health and the medical humanities, such as the Wellcome Library, London, the Special Collections and Archives at the University of Kent, and Blyth Gallery, Imperial College, University of London, my artists' books are experienced in teaching and research contexts to examine the body, health, illness, and wellbeing.

Defined by phenomenologists, the term embodiment "has a double sense: it encompasses both the body as a lived, experiential structure, and the body as the context or milieu of cognitive mechanism" (Varela, Thompson, and Rosch 1991, xvi). According to feminist theorists, such as Rosi Braidotti, "the body, or the embodiment, of the subject is to be understood as neither a biological nor a sociological category but rather as a point of overlapping between the physical, the symbolic, and the sociological" $(1994,4)$. "Embodiment thus indicates a holistic experiencing individual" (Barbour 2004, 229). But this perception of the body is relatively recent; as Elizabeth Grosz argues, "philosophy has established itself on a profound somatophobia" $(1994,5)$. Descartes' dualism demonstrates the achievement in "linking the mind/body opposition to the foundations of knowledge itself, a link which places the mind in a position of hierarchical superiority over and above nature, including the nature of the body" (Grosz 1994, 6), where consciousness is separated from nature.

This essay focuses on my books which communicate embodied knowledge in several ways: through phenomenological writing to give expression to my IBS and how it impacts on my teaching practice in Reflection on Digestion; through actual bodily material in Entrail Troyen 2014 and Entrail Troyen 2016; through the form and image of the digestive system in On Innards, Reflection on 
Digestion, and Entrail Troyen, particularly the concertina which emulates the bending and turning back of the intestines in the belly; and finally through the images of found objects that resemble coils of the bowels in Huwawa in the Everyday, the result of a mindfulness practice.

\section{The "Auratic Object": Reflection on Digestion 2012}

Reflection on Digestion explores digestion, the interior body, and embodied knowledge, emerging during my time on a Post-Graduate Teaching course. During a pedagogical research project in which I investigated my troubled digestive system in relation to my teaching practice, I generated text through autobiographical and fictional narrative and phenomenological methods; writing through lived experience in lecture theatres and tutorials, on buses, trains and tubes, within confined spaces that I didn't feel comfortable farting in. These texts were used as material, alongside other extracts about pedagogy and the body ${ }^{2}$ exploring the metaphors of reflection and digestion. Digestion stems from the word 'digest.' In addition to breaking down and absorbing food, to 'digest' can refer to an arrangement of written work (known as a 'digest') and to the processing or making sense of knowledge and experience (Figs. 1, 2, 3, 4 and 5).

Fig. 1

Amanda Couch, Reflection on Digestion, 2012. Eighteen pages of photo polymer relief printed on $410 \mathrm{gsm}$ Somerset Satin with calf skin binding and gold hotfoil. $50 \times 45 \times 900 \mathrm{~cm}$. Edition of 3. Made with a research award from The University for the Creative Arts (UCA) Farnham, and produced at bookroom press, Farnham 


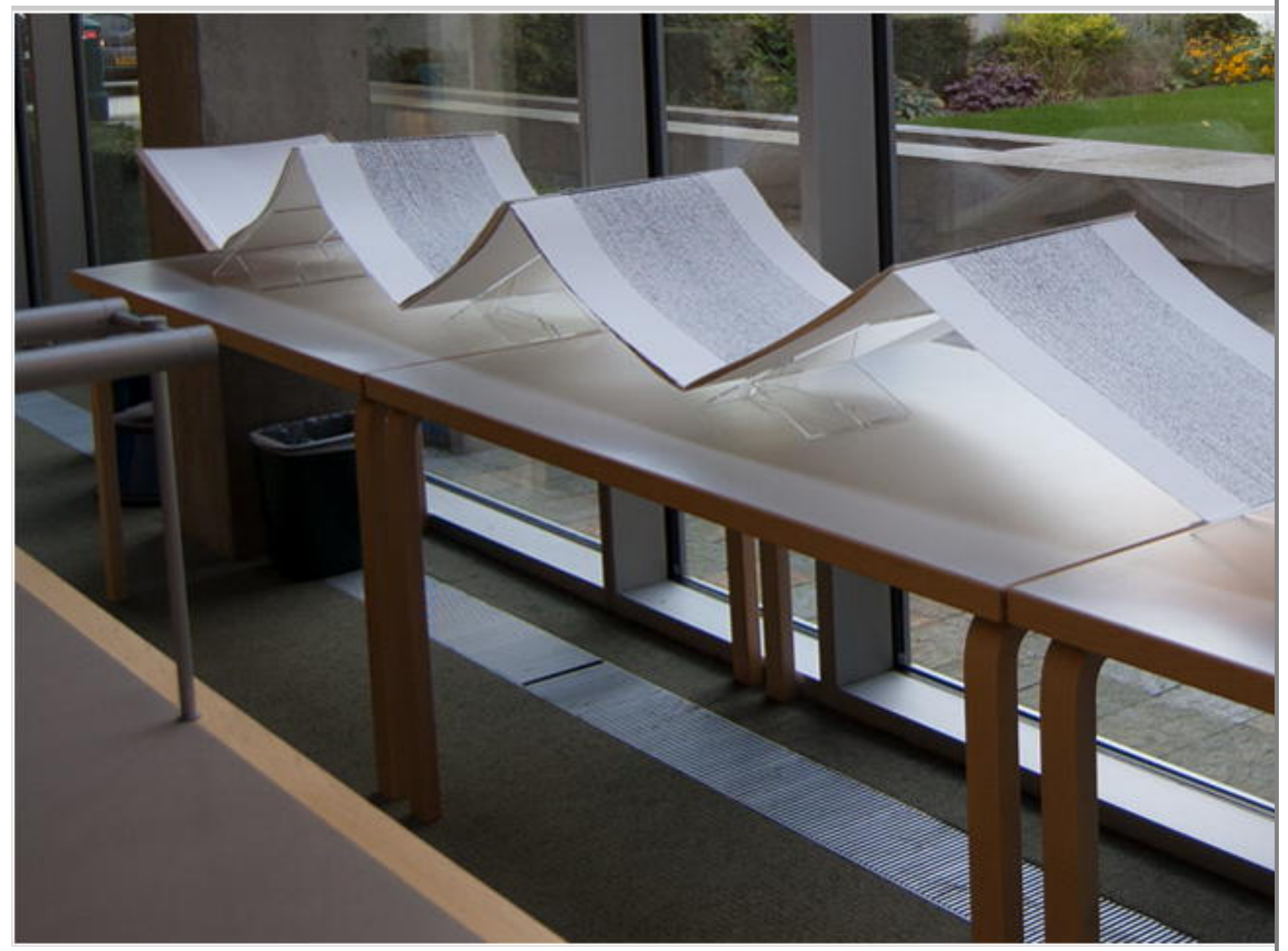

Fig. 2

Amanda Couch, Reflection on Digestion, 2012 (detail). Eighteen pages of photo polymer relief printed on $410 \mathrm{gsm}$ Somerset Satin with calf skin binding and gold hotfoil. $50 \times 45 \times 900 \mathrm{~cm}$. Edition of 3 . Made with a research award from The University for the Creative Arts (UCA) Farnham, and produced at bookroom press, Farnham 


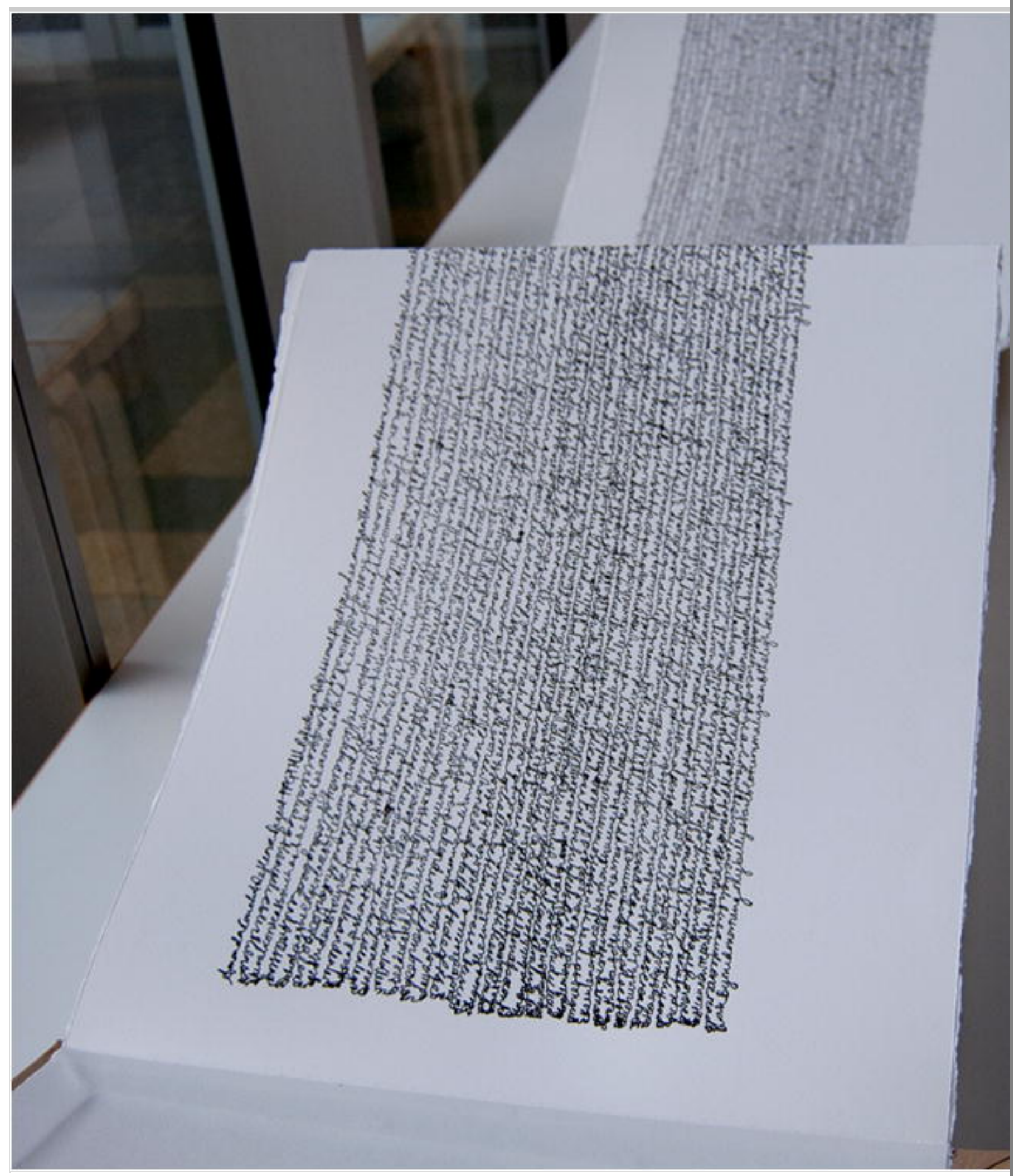

Fig. 3

Amanda Couch, Entrail Troyen 2014, left. Salami rind and sausage casings, toilet roll, cocktail sticks, glue. $150 \times 4 \times 4 \mathrm{~cm}$. Unique object, and Amanda Couch Entrail Troyen 2016 (detail), right. Double-sided inkjet print on variety of Japanese papers and weights, with salami skin collage and threads, bound in $300 \mathrm{gsm}$ Waterford folio with red wax seal. $178 \times 18.5 \mathrm{~cm}$. Edition of 25 


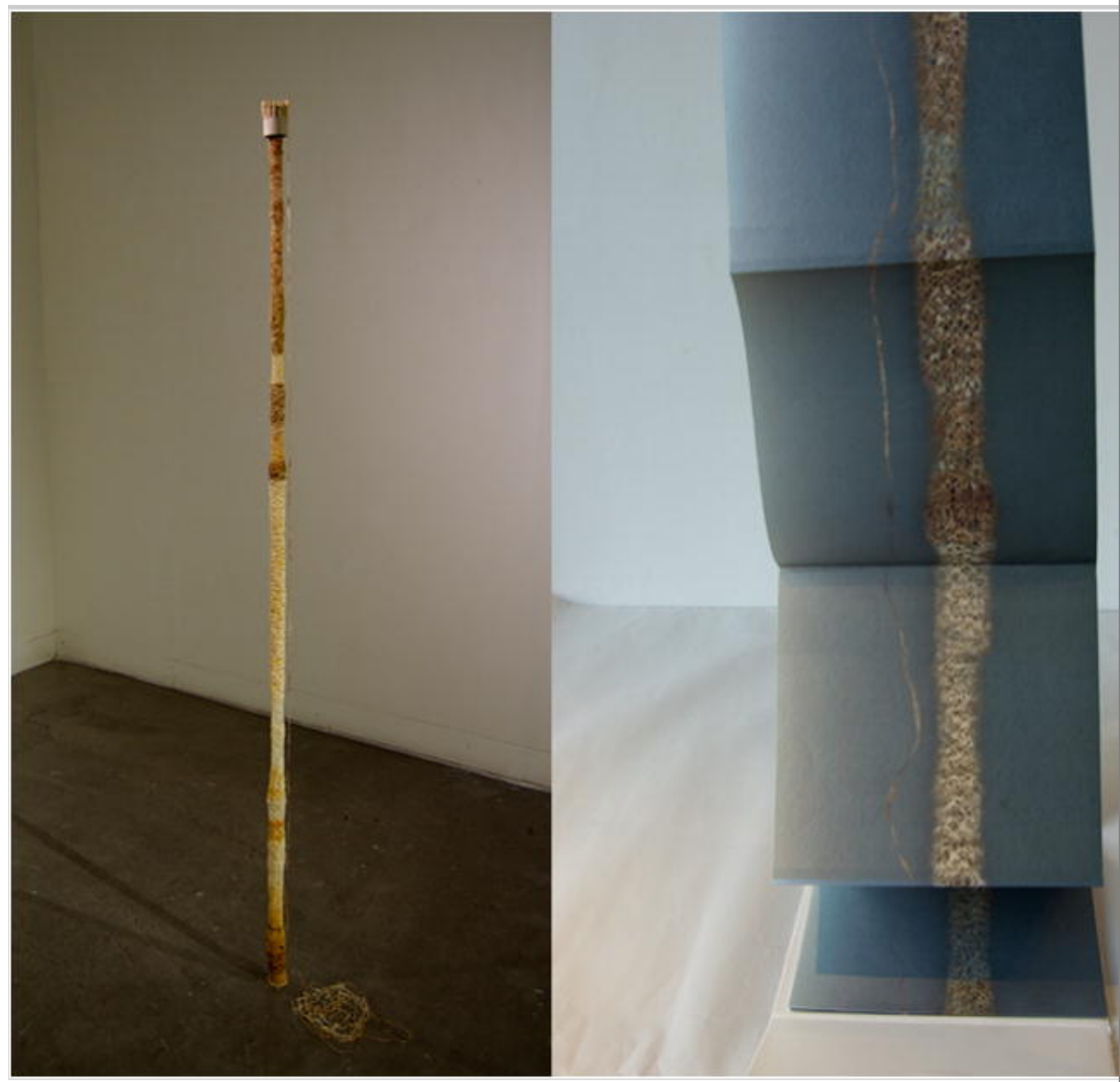

Fig. 4

Amanda Couch, Andrew Hladky, Mindy Lee, and Richard Nash On Innards Publication 2015. Textblock digitally printed by Riverprint on Colorplan 135 and 270 gsm stock by G. F. Smith. Manilla folder printed on an Epson R2000. Cut, folded, bound and finished by hand. Individually stamped and numbered. Published by bookRoom Press, Farnham. 200 pages of various intersecting formats and custom binding. $22 \times 27 \times 2 \mathrm{~cm}$. Edition of 200. Image credit: Mindy Lee 


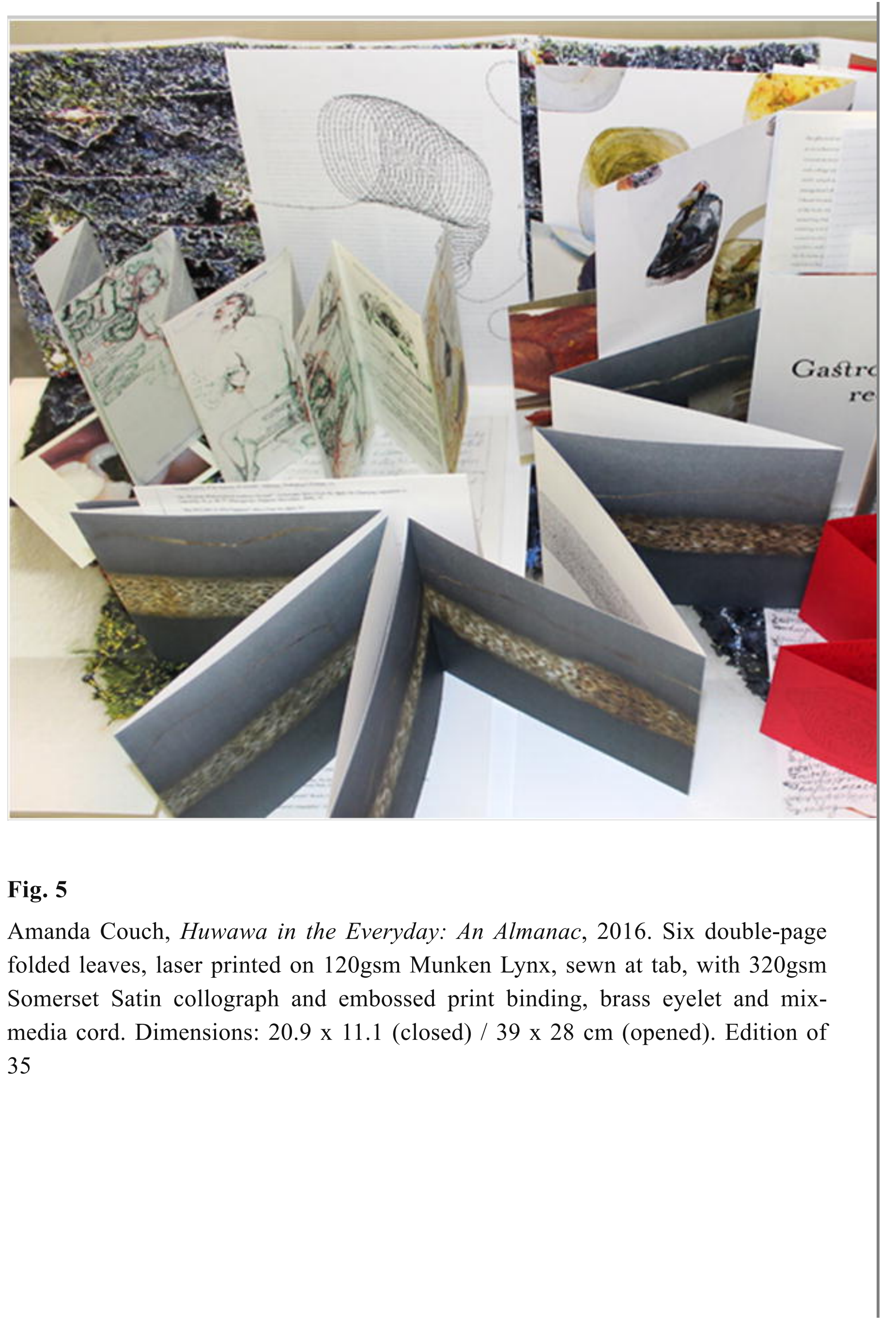




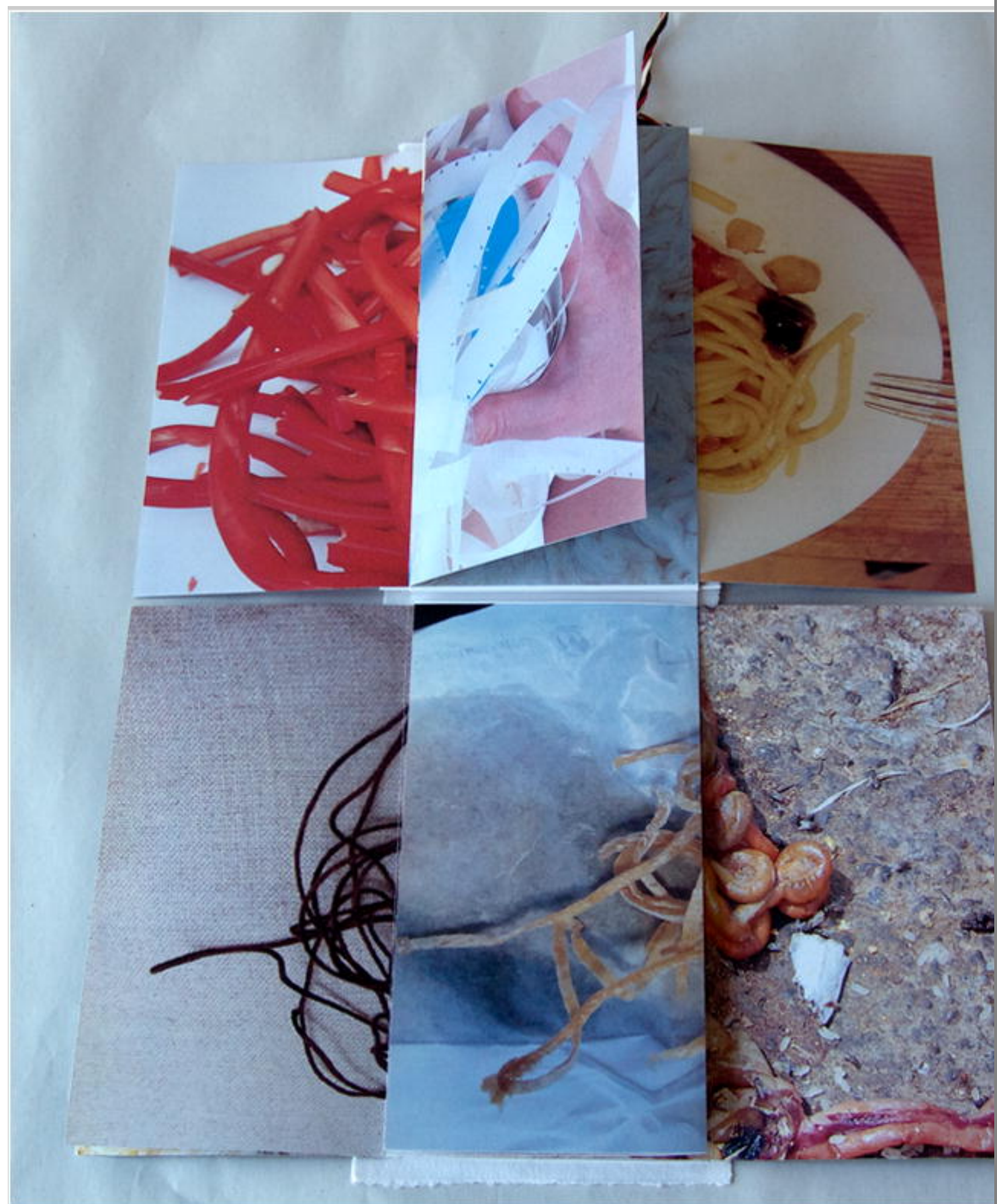

Through a series of performances over thirty-seven hours, during Book Live!, a symposium at London South Bank University ${ }^{3}$ and in the library at Wimbledon College of Art, London, these texts were scribed to generate a handwritten ninemeter-long manuscript. The document was then digitized and relief printed with 
photopolymer plates onto eighteen pages of $410 \mathrm{gsm}$ Somerset satin paper. Folded into a book block of approximately $50 \times 45 \mathrm{~cm}$, the concertina form was bound in calf-skin and Reflection on Digestion was stamped in gold hotfoil on the cover. ${ }^{4}$

I hope that I have made what Johanna Drucker calls an "Auratic Object," the kind of "book which [has] an aura about [it]" $(2004,13)$. Through the many weeks of research and labor, scribing, printing, and constructing, the piece is imbued with "an intense investment of obsessive work" (13). Through its making, and when exhibited, the scale, performativity and sculptural quality of Reflection on Digestion recalls the investigations of 1960s Fluxus movement, being "as much installation and performance as object" (13). Its title, Reflection on Digestion, is enacted through the turning of the pages back and forth, recalling the meaning of reflection as "a bending back" (Etymonline 2018), as well as through the accordion format, itself, an embodiment of the digestive system, emulating the alimentary tract within the belly cavity.

The cursive text has no spaces, a scripto continua, which runs across and back along its nine-meter length. Each word is tied to the previous, to the next, and to the subsequent line, from left to right, then upside down right to left. Writing in a curve or "ox turning"5 at the edges of the book, the bends also recall medical diagrams of coiled intestines. They further reference texts written in a continuous script in classical Greek and Latin and those from the early Christian era, where there was no spacing or punctuation for taking a breath between words. Texts were employed predominantly as memory joggers where the reader would already know the contents. Uttering the words aloud was essential for "readers to comprehend a script," so one was able to "listen where breaks might occur" (Littau 2006, 14).

For the medieval reader, according to Michael Camille, an art historian of the Middle Ages, "every turn of the page [was] an act of intense interpenetration and one resonant with sensations, from the feel of the flesh and hair side of the parchment on one's fingertips to the lubricious labial mouthing of the words with one's throat and tongue" $(1997,41)$. This was, in part, because reading was a corporeal event, a "bodily performance" (Frese and O'Keeffe 1997, xiii), or a "physical exercise” ( Jean Dom Leclercq Should be 'Dom Jean Leclercq' 1962, in Littau 2006, 36). However, from the eleventh century onwards reading became "silent and visual," "less corporeal" (Littau 2006, 15). Words were no longer heard by the ears, explored in the architecture of the mouth, or shaped, 
tasted and felt within the murmuring of the movement of tongue, jaw, and lips.

Duration, labor, and "bodily performance" (Frese and O'Keeffe 1997, xiii), embodied in the scribing/drawing as well as the printing and construction of the book, was re-written into the work's history through another example of "obsessive work" (Drucker 2004, 94) in a marathon performance of four and a half hours. "In Other Words" was curated by Rowan Lear, part of Bath Fringe Arts, which explored our "evolving relationship with text, language and writing" (Lear 2013). Denying myself food, drink and comfort breaks, I reanimated the text, navigating its awkward nine meters to read aloud my scripto continua. The writing/drawing is not easily legible, the lettering hovering between word and image, content and form. Attempting to decipher the words created an absurd narrative in which language is in one moment recognized, the next, nonsense.

Looking at the pages of Reflection on Digestion head on, the tops of the letters that face each other describe the boundaries and undulations of a tube, connoting the diagrammatic image we have of the gut. The loops and tails, ascenders and descenders resemble villi and microvilli that expand the intestinal mucosa, the surface of the small intestine. These folds of my cursive hand are depictions of language, drawings of actual words, at the same time text and image, a form of writing/drawing. Employing the term writing/drawing is informed by anthropologist, Tim Ingold's Lines: A Brief History in which he asserts, "so long as writing is understood in its original sense as a practice of inscription, there cannot be any hard-and-fast distinction between drawing and writing, or between the craft of the draughtsman and that of the scribe" (2007, $3)$. For arguably, until the invention of the printing press, "the very art of writing...lay in the drawing of lines" (128), and both drawing and writing, materialize by way of the "gesture - of pulling or dragging the implement - and the line traced by it" (43). Ingold deduces that the term 'to draw' infers connections between the "activity of hand both in the manipulation of threads and in the inscription of traces" (43).

\section{"Book as Object": Entrail Troyen 2014 and Entrail Troyen 2016}

The intestinal forms in the writing/drawing of Reflection on Digestion is echoed in the stitches that craft Entrail Troyen (2014), a 152-cm-long, tubular piece of French knitting, made with a portion of a toilet roll and cocktail sticks as a 
dolly, which Drucker might call the "hybridization of book as object" (2004, 13). Articulated loop by loop from a "thread" pieced together from a collection of salami skins, Entrail Troyen is named after a visit to the French city, Troyes, in the Champagne-Ardennes region, famous for its knitting and its Andouillette, a pork sausage made with twisted loops of chitterlings in a large intestine casing. A kind of script. A text and textile. A continual line of enquiry, knitting together a narrative embodied in the materiality of the "thread" fashioned from fragments of fiber that was once entrails. The charcuterie casings, gifted from friends and family and kept from numerous picnics whilst travelling through France one summer, are traces of commensality, infused with stories spoken whilst sharing food.

The word, fiber, aptly reflects Entrail Troyen's material origins, coming from the Latin fibra, meaning "a fiber, filament; entrails" (Etymonline 2018). The etymology of the word, entrails, reveals that as well as meaning the "internal parts of animal bodies" or "inward parts, intestines" (Etymonline 2018), it is an "entanglement," or "fold," with the verb, to entrail, meaning "to interweave; intertwine" (Wiktionary 2018), thus interlinking notions of text and textiles, yarns and storytelling.

The form and materiality of Entrail Troyen recalls Dieter Roth's series of Literaturwurst or "Literature sausage" (1961-70) in which he "reframed [...] sausages as books" (Suzuki 2013, 22). Playfully following the recipe for making sausages, Roth, in place of meat, used ground up books by Goethe or Marx, for example, stuffing them into casings with spices, gelatin and fat: an act that connects metaphorical and literal digestion, "commingl[ing] the ideas of books as nourishment; the physical sustenance of food is likened to the intellectual one of reading [...] suggest[ing] a means of ingesting and digesting information" (Suzuki 2013, 22). Alongside the "explicit literalizing of the metaphor of consuming a book as one consumes food" (Carruthers 2008, 208), there have also been recorded examples of actual eating of books, during the French Wars of Religion where, "wwite blank parchment, [...] letters, titledeeds, books printed and hand written [...]' were soaked, chopped, boiled for a day and a half, and then they were fricasseed like tripe, or cooked with herbs and spices" (Cunningham 2000, 229; in Purnis 2010, 16).

Entrail Troyen (2016) is a leporello depicting the life-size scan, recto and verso of the "book as object" (Drucker 2004, 13) bound in a Bockingford envelope. In 
creating the image, it was important that it was not a photograph shot with a single click of the camera shutter but rather an image captured on a horizontal flatbed scanner, the bulb passing across the bed, like a CT's X-rays surveying the body. Unlike today's complex medical imaging, those made with my domestic device retained manifold imperfections; each section is bathed in diffused light producing alterations in hues and tone. There are mismatches between portions and blurring as a result of the scanner's restricted depth of field, all of which heighten its corporeal quality.

The medical gaze alluded to here raises questions around notions of truth and objectivity in western science. The advancement of medical imaging, observing in evermore complexity the inside of the body, is a pursuit which dates back to the sixteenth and seventeenth century. In The Writing of History, Michel de Certeau speaks of this "dizzying" desire to witness the previously unseen body, making a connection between geographic and anatomical mapping, writing, "the frenzy of knowing and the pleasure of looking reach into the darkest regions and unfold the interiority of bodies as surfaces laid out before our eyes" (1988, 232). Present day, topographical anatomy, X-rays, ultrasound, computed tomography, and magnetic resonance imaging employ a system of topographic coordinates based on the principles of global cartography. Lines of latitude and longitudes are assigned to the surface of the body corresponding to the Greenwich Meridian (zero longitude). Mapping the body before clinical procedures enables a virtual unfolding of the interior body (Burykh 2004).

Sections of the original Entrail Troyen are stitched from the casings of various charcuterie (saucisson, salami, chorizo, bresaola), with their diverse colors, transparencies, weights, and strengths so the sections of each scan retain their nuances. Correspondingly different pages are printed on sheets of various fibers, tones, and weights of Japanese papers: Kozo, Mitsumata, Inbe, Okawara. At the bottom, image returns to matter with lengths of casing continuing the line, which is then threaded through the folio binding, and held with a wax seal depicting an anus, made in the same way as Wim Delvoye's Anus Kisses (19992000). After applying lipstick to my bum-hole, I lowered myself onto paper. The imprint was digitized and sent for etching by a seal making company. Stamping the anus seal in red wax acts as a full stop at the end of the book.

\section{"Catalogue as Artist's Book": On Innards 2015}

The On Innards project (2012-2015) is a collaboration with artists Andrew 
Hladky and Mindy Lee and more recently, as bookwork, published by bookRoom press, Farnham, with Richard Nash. As a multidisciplinary project, it explores the changing conceptualizations of guts and digestion, and the role they play in constructing and destabilizing our sense of self. On Innards' first outing was at the "Body Horror" Inter-Disciplinary.Net conference (2013) where we presented physical artwork, a performance, and a three-way discussion of our artistic practices and shared interests in guts, digestion, and subjectivity.

\section{On Innards $\mid$ Exhibition at Blyth Gallery, Imperial College, University of} London, followed a year later, consisting of painting, objects, drawing, and print. The show explored entrails and the digestive process as material, image, and metaphor, moving between representation and realism and making reference to phenomenologist Gaston Bachelard's claim that digestion "is the origin of the strongest kind of realism" $(2002,172)$. Central to the work was the desire to avoid the flattening effects of representation and encourage more embodied ways for people to encounter artwork. Accompanying the show was On Innards | Event a participatory and experiential day which brought researchers and practitioners from the fields of gastroenterology, virology, the medical humanities, cultural theory, poetic practice, and yoga to explore multidisciplinary perspectives on digestion and the interior body. ${ }^{6}$

On Innards | Publication (2015) could be classified as "the hybrid genre of the catalogue as artist's book" (Drucker 2004, 12). It is intestinal in form with a multitude of folds-concertinas, fold-outs, pop-ups, gate folds, roll folds, and reveals -held by a mesenteric binding, which when unwound, allows the book to be further unraveled to reveal hidden texts. It also references the archive: the buff cover cut from the simplest of manila folders mimics those used in hospitals and doctors' surgeries to house our myriad of medical notes. An overarching concertina creates six sections in each of the valley folds cradling over thirty booklets, pamphlets, and tracts, each pertaining to an artwork or contributor. Conceptually travelling from mouth to anus, it "construct[s] a metalanguage [...] a site of record, not only in a textual sense but also as a physical corporeal reality" (Drucker 2004, 104). One such section, a gate fold, interpreting the presentation by gastroenterologist Dr. Gabe, unveils like a fugitive sheet, the visceral interior of the gut during an operation.

The overarching "spine," a two-meter long double-sided concertina, documents the conversation of our overlapping interests. It is backbone in the sense of the 
anatomy of the book - the accumulation of folds when closed, form the spine of the book, acting as cradle supporting the other pamphlets-as well as metaphorically, as the surfaces of the pages reveal our motivations and reflections on the project in the form of questions and answers between the artists-curators. During development, Nash typeset our three-way conversation presented at the "Body Horror" conference and published in the e-book into narrow text blocks imitating the alimentary tract, engaging us to work into it through collage, drawing, painting, cutting, imprint, and inscription in the form of marginalia, annotations, revisions, and clarifications.

What transpired was the creation of a palimpsest. Historically, palimpsests were manuscripts made of parchment or vellum, which through the action of scraping and/or washing enabled surfaces to be re-used for new writing. Layers of the past were erased but not without leaving histories embedded in the skins. Our palimpsest exposes our ruminations and transformations in thinking and writing. For example, instead of scratching off the words which exposed his experience of an eating disorder and crisis of identity, Hladky collaged a photographic representation of the worm-like forms which constitute his paintings to obscure the details of

what, after reflection, he believed was too personal a confession of his digestive trials. Consequently, we were practicing another kind of palimpsest, the rewriting of a new self over the old and thereby re-authoring our personal narratives. As well as her extensive marginalia of tangential questions to trigger deeper reflection, Lee printed the surface with the "ink" of lipstick via the "plate" of the lips and the "press" of the jaw. This imprint can be inferred as a kind of "lip reading," with the upper lip on the edge of page one and the lower on the last. At the ends of the length of concertina, they act like square brackets which "are mainly used to enclose words added by someone other than the original writer [...] to clarify the situation" (Oxford Dictionaries Online 2018). In this case, the brackets are enfolding the conversation on the reverse involving Nash who joined On Innards to develop it as book. Here, he reflects on his role from the perspective as designer, paper engineer, and wordsmith, and particularly how "the subject of digestion" will continue to shape his own practice, imbuing it with a renewed sense of embodiment. As he reveals, "the consideration of intestines and digestion [...] has become analogous for the written word; through reading as a process of digestion as well as the visual presence on the page" (2015). 
Writing of the palimpsest in his essay, "The Revelation of Erasure," critic Brian Dillon (2006) proposes "there is something seductive about the idea of an erased truth lurking between the lines." Like the palimpsest where older texts lay behind the scenes their ghost-like presences embodied in the material, the gut lurks beneath the veil of our conscious awareness yet exercising influence. It is a kind of "erased truth," which, since the Enlightenment, our modern cerebro-centered world has attempted to write over. The importance of the digestive system on pre-modern conceptualizations of self is being unearthed by scholars of early modern literature such as Jan Purnis (2010a, b) and David Hillman (2007) and in neuro-gastroenterology. Dr. Michael Gershon (1998) states that the enteric nervous system or "second brain" works both with our brains in our heads as well as autonomously. And because it is at the same time interior and exterior, outside the body border, it can sense environmental dangers prompting us to respond accordingly. The gut then is re-emerging as the site of our most direct and complex physical exchange with the external world (Gershon 1998).

\section{"Book as Performance": Huwawa in the Everyday: An Almanac 2016}

Part of a "class of small manuscripts that contains calendrical, astrological, and medical elements, and which appears to have been designed to hang from the belt" (Carey 2003, 482), the medieval English folding almanac was usually employed by physicians to prognosticate and diagnose. Hilary Carey, an expert on these manuscripts, argues that the practice of astrology was at the heart of medieval medicine and was essential in order to grasp a deep knowledge of the body as well as when and how to treat its ails. Medical treatments would have been guided by astrological knowledge and interpretation of the position of the celestial bodies at particular times. Carey writes that "an understanding of the calendar and the timing of medical procedures, from the collection of drugs to the administration of medicine, purges, fasting, bleeding, and cautery, was another portal through which medical practitioners were exposed to the principles of astrology" $(2004,350)$.

The artist's book, Huwawa in the Everyday: An Almanac, makes reference to these artifacts, particularly the Wellcome Library's MS.8932 English folding almanac in Latin. MS.8932 contains seven vellum leaves, each of which fold once in half and then into thirds, in a roll fold, forming six rectangular portions. It measures $3.8 \times 16 \mathrm{~cm}$ when closed and is bound in ornate green and pink 
embroidered silk. The leaves contain a Zodiac Man diagram, which connects parts of the body with its corresponding astrological sign, lists of feast days, lunar and solar eclipses of the period, and calculations of the planetary hours.

Huwawa in the Everyday is a photobook of twelve images, one for each of the houses that divide the horoscope, depicting actual entrails or coiled materials which resemble guts encountered in the everyday. These photographs are laser printed, landscape, recto and verso, onto six leaves of $120 \mathrm{gsm}$ Munken Lynx paper, $39 \times 28 \mathrm{~cm}$, folded vertically in a roll fold becoming $21 \times 11 \mathrm{~cm}$ when closed. Bound in 320gsm Somerset Satin, the spine is formed at the top of the middle portion. The cover image is embossed and collagraph printed in dark brown ink. The text employs a simple embroidered script taken from the Bayeux Tapestry, and a stitched line depicts the Mesopotamian divination model of the demon Huwawa in the British Museum, which portrays the demon's face as coiled intestines. ${ }^{7}$ Both are embroidered onto linen and then glued onto card and varnished. These textile processes reference the cover of the Wellcome Library's manuscript.

Whilst not directly illustrating medical or astrological information, my interpretation draws on the connection between astrology, divination using the stars and planets, and the practice of extispicy, divination using the entrails. It is thought that both forms of deductive divination, in which one observes natural phenomena, astrology and extispicy were the two most important and widespread forms of divinatory practice in ancient times (Koch 2011, 447). Each drew on the other, operating, as philosopher and art historian Georges Didi-Huberman argues, like "a sidereal-anthropomorphic correspondence; that is, the "transferring of the cosmic system onto man" $(2010,23)$. He writes, "the folds of the animal body offered the possibility "to read what was never written" in the map of the sky and in the body of the gods" $(2010,26)$.

Huwawa... can be carried on the person, attached to a belt with the almanac's threads, and used as a prompt during daily activities, "to see acutely, to notice, to make connections" (Stilgoe 1998, 3). In "making the audience member a performer" (Drucker 2004, 311), you are encouraged to perceive entrails in the world and at the same time, to sense your insides within. Images include: a plate of spaghetti; giant strawberry cables; a bundle of blue and white film and audio leader tape; a yellow garden hose; a pile of black electricity cables; and a film still of character Kracklite in Peter Greenway's film, Belly of an Architect (1987) holding red tubing, foregrounding that the alimentary canal is both 
inside the body and also a tube that runs through it, part of the external environment.

Contingent on the reader's engagement, through the unfolding and folding of the leaves, the images fragment, conflating with those above, below, opposite and on the reverse, creating new composites like the collaborative drawing game Exquisite Corpse, ${ }^{8}$ which was "much appreciated by the surrealists for [its] disruption of everyday logic" (Tate n.d.). In the reader's interaction with Huwawa ... aspects of the coincidental which were integral in the noticing and collecting of the images for the book are engaged once again.

Bound up in the observing and documenting of materials that resemble guts is the faint hope that we may see Huwawa (reflected by the gods or by chance). But this is perhaps less a search for the exact form but rather another kind of reflection: A sharpening of one's sensitivity to such materials and forms enables us to re-think our relationship with the world; to dissolve hierarchies of self and other and boundaries of inside and outside. As Elizabeth Grosz writes:

The body provides a point of mediation between what is perceived as purely internal and accessible only to the subject and what is external and publicly observable, a point from which to rethink the opposition between the inside and the outside, the private and the public, the self and the other, and all the other binary pairs associated with the mind/body opposition. (1994, 20)

The further search for the coils to resemble the face of Huwawa connects the materials of my work and found objects and matter in the everyday with ideas that are more politically charged such as revolution. The inscription on the reverse of the model of Huwawa's face reveals an omen that if entrails were encountered that look like this model, it would mean "revolution." The radical side of guts was further emphasized at a talk on "Fermentation: activism on the margins" by Darren Ollerton of Octopus Alchemy ${ }^{9}$ in July 2015, as part of Karen Guthrie/Grizedale Arts' House of Ferment ${ }^{10}$ at London's Science Gallery's exhibition FED-UP: The Future of Food. As a consequence of a severe illness and a consequent disillusionment with the biomedical approach to his care, diagnosis, and treatment, Ollerton practices and teaches fermentation as radical politics, offering a simple jar of kimchi or sauerkraut as a symbol for 
a bigger critique of food and health economies. When he spoke about the gut being at the center of a revolutionary politics, I felt a flutter of butterflies agitate within my belly!

Seeping into daily life, the artist's book Huwawa... and its associated activities becomes a feminist durational performance practice, which helps me to stay present, "the only reality we actually have" (MAI 2016), and to mitigate against anxiety: the unwanted, obsessive and repetitive thoughts I sometimes experience. The practice cultivates an "awareness that builds into mindfulness, into the enduring pleasures of noticing and thinking about what one notices" (Stilgoe 1998, 18), enabling me to "diagnose" as in the original sense of the meaning of the word: from gnostic meaning "to learn" or "to come to know" the world (Etymonline 2018) and my place within it.

\section{Conclusion}

Michael Camille's portrayal of the experience of reading and handling books in the Middle Ages is akin to many of the motivations of makers and beholders of artists' books today. In my artists' books discussed here, the body is ever present through the materials, images within, and the actions that made, and encounter them. It is embodied in the actual intestines of sausage casings in Entrail Troyen 2014 and 2016, through the images collected of guts in Huwawa ..., and in images of insides and shit, for example in On Innards. It is further embodied in the recording of my lived experience of IBS and the action of scribing it in Reflection on Digestion, as well as through the concertina form, an embodiment of the folded intestines.

All of my artists' books could be classified as "Book[s] as Performance," acting as "the performance as well as containing it"; rather than reading, one "enacts" them (Drucker 2004, 311). Whether it be through the "bodily performance" (Frese and O'Keeffe 1997, xiii) of the turning of the pages of Reflection on Digestion in order to read its text out loud or in the nervous navigation of $O n$ Innards when unravelling its binding and unfolding its multiple tracts or in the wearing and employment as guide to noticing images of guts in Huwawa ..., the beholder is performer in her encounter with them. For Stella Bolaki, artists' books are more "than a mere container for ideas" $(2017,4)$. Artists' books marry form with subject, "invit[ing] handling, touching and interaction" (Hall $2003,14)$, to enable the body to speak. In my books, the body asserts its voice through form, materiality, action, intention, and tactility, activating a 
performance space between maker and beholder, bidding us "to attend to our own embodied experience" (Bolaki 2017,7), to enact situated ways of knowing and becoming.

Endnotes ${ }^{1}$ For more information on Martha Hall, see Jennifer Tuttle and Cathleen Miller's essay in this special issue.

2 For example, Bresler, Liora, ed. 2004. Knowing Bodies, Moving Minds. Dordrecht: Kluwer; Austerlitz, Noam, ed. 2008. Unspoken Interactions: Exploring the Unspoken Dimension of Learning and Teaching in Creative Subjects. London: The Centre for Learning and Teaching in Art and Design; Smears, Elizabeth. 2009. "Breaking Old Habits: Professional Development through an Embodied Approach to Reflective Practice." Journal of Dance and Somatic Practices 1 (1): 99-110.

${ }^{3}$ Book Live!, London South Bank University (LSBU), 7-8 June 2012: Convened by the Richard Sawdon Smith, Centre for Media and Cultural Research at LSBU and Emmanuelle Waeckerlé, bookroom, UCA Farnham.

${ }^{4}$ Materials, printing and construction was funded by a Research Award from University for the Creative Arts (UCA), including technical support from Jonathan Jarvis in UCA Farnham's print workshop, and bookRoom's bookmaking facilities.

5 The word boustrophedon means "ox-turning" from the Greek bous meaning "ox" and strophe meaning "turn," referencing an animal turning at the edge of field when ploughing.

${ }^{6}$ Contributors to the event and publication are Carlo Comanducci, film scholar; Giskin Day, medical humanities teacher; Dr Simon Gabe, gastroenterologist; Kerry Gallagher, yoga teacher; Nathaniel Storey, microbiologist; Jamie Sutcliffe, writer and artist.

${ }^{7}$ Huwawa or Humbaba was the monster in the Gilgamesh Epic who protected the Cedar forest.

${ }^{8}$ Invented in 1925 by the Surrealists, cadavre exquis or Exquisite Corpse is a visual form of the parlor game Consequences. Participants draw parts of the body in turn on a piece of paper, which before being passed to the next person is folded to conceal the marks made, resulting in a collaborative hybrid drawing. 
(Tate n.d.)

${ }^{9}$ Octopus Alchemy, now Alchemy Flow, based in Brighton, UK, supports and teaches fermentation. http://alchemyflow.com/workshops/

${ }^{10}$ House of Ferment is a project created by Cumbrian-based artist Karen Guthrie in collaboration with arts project Grizedale Arts, centering around the sculpture of a mountain as a mobile larder, and the transmitting "cultures" of fermenting knowledge.

\section{Publisher's Note}

Springer Nature remains neutral with regard to jurisdictional claims in published maps and institutional affiliations.

\section{References}

Ahmed, Sara and Stacey, Jackie. 2001. "Introduction: Dermographies." In Thinking through the Skin, edited by Sara Ahmed and Jackie Stacey, 1-17. London: Routledge.

Austerlitz, Noam, ed. 2008. Unspoken Interactions: Exploring the Unspoken Dimension of Learning and Teaching in Creative Subjects. London: The Centre for Learning and Teaching in Art and Design.

Bachelard, Gaston. 2002. Formation of the Scientific Mind. Manchester: Clinamen.

Barbour, Karen. 2004. "Embodied Ways of Knowing." Waikato Journal of Education 10: 227-238. Accessed 7 June 2018. doi: https://doi.org/10.15663/wje.v10i1.342 .

Bolaki, Stella. 2017. "The Material Power of Artists' Books: How Books Can Speak About Illness and Care." In Prescriptions: Artists'Books on Wellbeing and Medicine, edited by Stella Bolaki and Egidija Ciricaite, 4-10. London: Natrix Natrix Press.

Braidotti, Rosi. 1994. Nomadic Subjects: Embodiment and Sexual Difference 
in Contemporary Feminist Theory. New York: Columbia University Press.

Brenner, Elma. 2014. "The Enigma of the Medieval Almanac." Wellcome Library Blog, 6 January. Accessed 11 January 2018.

http://blog.wellcomelibrary.org/2014/01/the-enigma-of-the-medievalalmanac/ .

Bresler, Liora, ed. 2004. Knowing Bodies, Moving Minds. Dordrecht: Kluwer.

Burykh, MP. 2004. "Topographic Approach to the Study of the Human Body." Clinical Anatomy 17 (5): 423-428. doi:

https://doi.org/10.1002/ca.10251.

Camille, Michael. 1997. "The Book as Flesh and Fetish in Richard de Bury's Philoblion." In The Book and the Body, edited by Dolores Warwick Frese and Katherine O'Brien O'Keeffe, 33-77. Notre-Dame: University of NotreDame Press.

Carey, Hilary M. 2003. "What is the Folded Almanac?: The Form and Function of a Key Manuscript Source for Astro-medical Practice in Later Medieval England." Social History of Medicine 16 (3): 481-509.

---. 2004. "Astrological Medicine and the Medieval English Folded Almanac." Social History of Medicine 17 (3): 345-363.

Carruthers, Mary. 1997. "Reading with Attitude, Remembering the Book." In The Book and the Body, edited by Dolores Warwick Frese and Katherine O'Brien O'Keeffe, 1-33. Notre-Dame: University of Notre-Dame Press.

---. 2008. The Book of Memory: A Study of Memory in Medieval Culture. Cambridge: Cambridge University Press.

de Certeau, Michel. 1988. The Writing of History. New York: Columbia University Press.

Didi-Huberman, Georges. 2010. "I. Disparates: To Read What Was Never Written." In Atlas: How to Carry the World on One's Back?, edited by Georges Didi-Huberman, 14-59. Madrid: Museo Nacional Centro de Arte 
Reina Sofía.

Dillon, Brian. 2006. “The Revelation of Erasure." Tate Etc. 8. Accessed 10 January 2018. http://www.tate.org.uk/context-comment/articles/revelationerasure .

Drucker, Johanna. 2004. The Century of Artists'Books. New York: Granary Books.

Etymonline. 2018. Online Etymology Dictionary. Accessed 19 January 2018. https://www.etymonline.com/ .

Frese, Dolores Warwick and Katherine O'Brien O'Keeffe. 1997.

"Introduction." In The Book and the Body, edited by Dolores Warwick Frese and Katherine O'Brien O'Keeffe, ix-xviii. Notre-Dame: University of NotreDame Press.

Gershon, Michael. 1998. The Second Brain. The Scientific Basis of Gut Instinct and a Groundbreaking New Understanding of Nervous Disorders of the Stomach and Intestine. New York: Harper Perennial.

Grosz, Elizabeth. 1994. Volatile Bodies: Toward a Corporeal Feminism. Bloomington: Indiana University Press.

Hall, Martha. 2003. Holding In, Holding On. Northampton MA: Smith College/Herlin Press.

Hillman, David. 2007. Shakespeare's Entrails: Belief, Scepticism and the Interior of the Body. Basingstoke: Palgrave Macmillian.

Ingold, Tim. 2007. Lines: A Brief History. Abingdon: Routledge.

Koch, Ulla Susanne. 2011. "Sheep and Sky: Systems of Divinatory Interpretation." In The Oxford Handbook of Cuneiform Culture, edited by Karen Radner and Eleanor Robson, 447-469. Oxford: Oxford University Press.

Lear, Rowan. 2013. "In Other Words.” Accessed 19 January 2018. https://inotherwordsbath.wordpress.com/in-other-words/ . 
Littau, Karin. 2006. Theories of Reading: Books, Bodies and Bibliomania. Cambridge: Polity Press.

MAI/Marina Abramovic Institute. 2016. "Abramovic, Marina: A lecture on 'The History of Long-Durational Work,' Tuesday, March 22nd 2016".

Marina Abramovic Institute. Accessed 11 January 2018. https://mai.art/asone-content/2016/4/6/history-of-long-durational-work .

Oxford Dictionaries Online. n.d. Accessed 9 February 2018. https://en.oxforddictionaries.com/ .

Purnis, Jan. 2010a. "Digestive Tracts: Early Modern Discourses of Digestion." PhD diss., University of Toronto. Accessed 22 February 2018. https://tspace.library.utoronto.ca/bitstream/1807/33822/1/Purnis_Jan_K_201011_P

Purnis, Jan. 2010b. "The Stomach and Early Modern Emotion." University of Toronto Quarterly 79 (2): 800-818. doi:

https://doi.org/10.1353/utq.2010.0228 .

Smears, Elizabeth. 2009. "Breaking Old Habits: Professional Development through an Embodied Approach to Reflective Practice." Journal of Dance and Somatic Practices 1 (1): 99-110.

Stilgoe, John R. 1998. Outside Lies Magic: Regaining History and Awareness in Everyday Places. New York: Walker and Company.

Suzuki, Sarah. 2013. Wait, Later This Will Be Nothing: Editions by Dieter Roth. New York: The Museum of Modern Art.

Tate. n.d. "“André Breton, Nusch Eluard, Valentine Hugo, Paul Eluard, Exquisite Corpse' c.1930.” Accessed 9 February 2018. http://www.tate.org.uk/art/artworks/breton-eluard-hugo-exquisite-corpset12005.

Varela, Francisco J., Thompson, Evan, and Rosch, Eleanor. 1991. The Embodied Mind: Cognitive Science and Human Experience. Cambridge, MA: MIT Press.

Wellcome Library. 2014. MS.8932, English folding almanac in Latin. 
Accessed 19 January 2018. https://wellcomelibrary.org/item/b20605055\#? $\mathrm{c}=0 \& \mathrm{~m}=0 \& \mathrm{~s}=0 \& \mathrm{cv}=0$.

Wikipedia. 2018. Accessed 19 January 2018. https://en.wikipedia.org/ .

Wiktionary. 2018. Accessed 19 January 2018. https://en.wiktionary.org/ . 